\title{
Effect of Laser Welding Speed on Grain Morphology and Tensile Property of TA15 Titanium Alloy Bottom- Locking Joint
}

\section{Jiayao Wang}

Nanjing University of Aeronautics and Astronautics

$\mathrm{Na}$ Qi

Nanjing University of Aeronautics and Astronautics

Yanqiu Zhao

Nanjing University of Aeronautics and Astronautics

Yue Li

Nanjing University of Aeronautics and Astronautics

Xiaohong Zhan ( $\nabla$ xiaohongzhan_nuaa@126.com )

Nanjing University of Aeronautics and Astronautics

\section{Research Article}

Keywords: TA15 titanium alloy, Bottom-locking joint, Welding speed, Tensile strength

Posted Date: July 30th, 2021

DOl: https://doi.org/10.21203/rs.3.rs-745986/v1

License: (c) (i) This work is licensed under a Creative Commons Attribution 4.0 International License. Read Full License 


\section{Abstract}

The laser welding of TA15 titanium alloy with the bottom-locking joints is carried out by TruDisk-12003 disc laser. In this paper, the microstructure and tensile properties of welded joints with different welding speeds are studied. The microstructure is observed by optical microscope. The tensile fracture morphology and chemical composition are analyzed by scanning electron microscope (SEM) and energy dispersive spectrometer (EDS) respectively. The experimental results show that the width of weld zone (WZ) is decreased significantly with the increasing of welding speed. The $\beta$ columnar crystal shows respective morphology and growth direction in WZ under different welding speeds, meanwhile, the number of acicular martensite which is precipitated in columnar crystal also presents different. Besides, the aggregate growth zone of columnar crystal at the bottom of weld zone gets smaller with the increase of welding speed. The maximum tensile strength for the TA15 titanium alloy bottom-locking joint, which is fractured at weld joint, reaches $89 \%$ of the BM. Besides, the EDS results illustrate that the burning loss of stabilization element is inevitable.

\section{Introduction}

With the rapid development of aerospace industry [1], the requirements of important structures for light weight and the comprehensive performance have become increasingly demanding targets [2]. As one kind of light metal, titanium alloy has been widely and successfully used in aerospace field due to its excellent properties of high strength, corrosion resistance and outstanding temperature resistance [3-5]. TA15 titanium alloy, which is provided with excellent thermal stability and welding performance, applies widely in the welding parts of aerospace engines and military industries [6-7]. Therefore, it is the connection of titanium alloy that is necessarily involved in manufacturing. There are many methods developed in the welding of titanium alloys, such as gas tungsten inert gas (TIG) welding, laser beam welding (LBW) and electron beam welding (EBW) [8]. Compared with other welding methods, laser welding is characterized by concentrating energy, narrow heat affected zone (HAZ) and slight deformation after welding [9-10]. Besides, laser welding, which requires high assembly clearance and performs high speed, is suitable for the connection of structures with different thickness. Even welding structure with different thicknesses, the bottom-locking joint can be used to facilitate assembly and avoid gaps after welding.

Numerous studies about laser welding of TA15 alloy have been performed recently and a great number of research results have been proposed. Zhang et al. [11] studied the influence of laser beam migration on weld shape, grain size, micro-hardness and tensile strength of welded joints for BTi-6431S/TA15 dissimilar alloy. The results showed that the laser beam migration makes the cross-section of the joint asymmetric and the micro-hardness reach the peak value. Zhan et al. [12] carried out the titanium alloy laser welding orthogonal test and discussed the relationship between the heat input and microstructure. In addition, the reasonable process parameters of laser welding of TA15 alloy were optimized. Shen et al. [13] used single-beam and double-beam laser welding technology to weld $2 \mathrm{~mm}$ thick Ti-22Al-25Nb/TA15 dissimilar alloy plates, and systematically compared the morphology, micro-structure and mechanical 
properties of the welded joints analysis. The results showed that the hardness of the weld, the tensile strength and elongation were all increased under dual-beam laser welding compared with those under single-beam laser welding. Wang e al. [14] studied the hot deformation mechanism of the laser welding joint of TA15 titanium alloy by means of hot tensile test and concluded that the hot deformation mechanism of laser welded joint of TA15 alloy was continuous spheroidization. The results also showed the phase transition and dynamic recrystallization of $\alpha-\beta$ had great influence on the continuous spheroidization process.

Xu et al. [15] studied the microstructure and mechanical properties of laser welded TC4/TA15 dissimilar titanium alloy butt joints under different laser power and welding speed. And according to the results, the HAZ was composed of initial a phase and transformed $\beta$ structure and the tensile strength of TC4 / TA15 dissimilar titanium alloy welded joint was between that of the two base metals under different welding parameters. Li et al. [16] studied the influence of laser spot spacing and power ratio on the microstructure and properties of Ti-22Al-25Nb and TA15 alloy welded joint. The results indicated that the content and size of $O$ phase in the fusion zone were related to the transformation of $B_{2}$ phase into $O$ phase and the extension of $O$ phase growth time. Liu et al. [17] carried out laser-TIG hybrid welding of TA15 titanium alloy, and analyzed the microstructure and tensile properties of the welded joint. The Ti, Al, Mo, $\mathrm{V}$ and other elements were evenly distributed in the weld, and the tensile strength of the joint was almost close to that of the BM according to the results.

Many research work of TA15 titanium alloy welding has performed, but less on titanium alloy bottomlocking structure which is employed widely in connecting the skin and stringer. There is an obvious wide research space on laser welding of TA15 bottom-locking joint. In this paper, the laser welding experiments of TA15 titanium alloy bottom-locking structure under different welding speed are carried out. The effect of welding speed on the microstructure and tensile property of the welded joint is analyzed. It is expected to provide a basic understanding for the welding process of bottom-locking structure and promote the application of TA15 titanium alloy.

\section{Experimental Details}

\subsection{Materials and Apparatus}

The bottom-locking laser welding experiments are carried out on the TA15 titanium alloy plate with a dimension of $100 \mathrm{~mm} \times 50 \mathrm{~mm} \times 2 \mathrm{~mm}$ and $100 \mathrm{~mm} \times 50 \mathrm{~mm} \times 1.5 \mathrm{~mm}$. And the material used in this study has good weld-ability and high temperature performance of a titanium alloy as well as fine process plasticity of $\alpha+\beta$ titanium alloy [18-19]. The nominal composition of TA15 titanium alloy is Ti-6.5Al-2Zr$1 \mathrm{Mo}-1 \mathrm{~V}$ and the specific chemical compositions are shown in Table 1. It needs to be explained that the strength of this kind of titanium alloy is enhanced by adding high content of aluminum elements with stable a phase effect, and the process-ability is improved by adding neutral elements $\mathrm{Zr}$ as well as stable 
elements Mo and $\mathrm{V}$. The schematic of laser welding process, including the diagram of laser bottomlocking welding shown in Fig. 1 (a), the schematic diagram of welding joint shown in Fig. 1 (b) and the schematic diagram of basic dimensions shown in Fig. 1 (c). Due to the different thickness of the two plates used in this study, it is a heel block that needs to be installed on the side of the thin plate before welding to keep the same height. For a tight connection, the two plates also requires to be fixed with special laser welding fixtures. In this welding experiment, the bottom-locking structure is adopted without groove preparation and filling wires during the welding process.

Table 1

Chemical composition of TA15 alloy (wt.\%)

\begin{tabular}{|lllllllllll|}
\hline Al & Zr & V & Mo & O & Fe & Si & C & N & H & Ti \\
\hline 6.82 & 2.16 & 1.8 & 1.47 & 0.054 & 0.046 & 0.046 & 0.011 & 0.0069 & 0.0024 & Balanced \\
\hline
\end{tabular}

The bottom-locking laser welding experiments of TA15 alloy are mainly performed by the the KR $60 \mathrm{HA}$ robot with six-axis linkage system, TruDisk-12003 disc laser and the special fixture. The schematic diagram of laser welding experimental equipmentas are shown respectively in Fig. 2 . The laser beam is produced by a $12 \mathrm{~kW}$ disc laser and transmitted to the laser welding head with the optical fibers.

\subsection{Experimental design and process}

The weld plates are clamped and the position of the welding robot is adjusted before welding. After completion, the data listed in Table 2 are employed as the weld parameters. According to the table, three different speeds are used during the bottom-locking welding, which are $1 \mathrm{~m} \cdot \mathrm{min}^{-1}, 1.2 \mathrm{~m} \cdot \mathrm{min}^{-1}$ and $1.5 \mathrm{~m} \cdot \mathrm{min}^{-1}$ respectively. Meanwhile, the laser power is maintained at $1000 \mathrm{~W}$. Besides, the shielding gas is required on both the upper and back sides of the weld in order to achieve good welding quality. The flow rate of upper protection is $20 \mathrm{~L} \cdot \mathrm{min}^{-1}$ and that of back protection is $15 \mathrm{~L} \cdot \mathrm{min}^{-1}$.

Table 2

Parameters of TA15 titanium alloy bottom-locking laser welding

\begin{tabular}{|lllll|}
\hline Case & $\begin{array}{l}\text { Welding } \\
\text { speed } \\
/\left(\mathrm{m}^{\prime} \mathrm{min}^{-1}\right)\end{array}$ & $\begin{array}{l}\text { Laser } \\
\text { power }\end{array}$ & $\begin{array}{l}\text { Upper gas flow rate/(L·min } \\
\mathbf{1})\end{array}$ & $\begin{array}{l}\text { Back gas flow rate/(L·min } \\
1)\end{array}$ \\
\hline 1 & 1.0 & 1000 & 20 & 15 \\
\hline 2 & 1.2 & 1000 & 20 & 15 \\
\hline 3 & 1.5 & 1000 & 20 & 15 \\
\hline
\end{tabular}

Completing the laser welding process, the line cutting machine is employed to cut weldments in order to carry out the subsequent metallographic pattern preparation and tensile test. The cross section of weld seam is cut off to observe the microstructure. Before that, the Cases are prepared by using standard metallographic procedure and etched with $\mathrm{Kroll}\left(2 \% \mathrm{HF}+4 \% \mathrm{HNO}_{3}+94 \% \mathrm{H}_{2} \mathrm{O}\right)$ reagent subsequently until 
the grain boundary appears. The shape of the weld interface is observed by optical microscope. The tensile properties of the weld seam are measured by the universal testing machine (UTM) 5105 carrying out tensile test. Besides, SEM is adopted to further study the fracture morphology of bottom-locking joint and EDS is utilized to detect the chemical compositions of fracture surface.

\section{Result And Discussion}

\subsection{Macro morphology of weld joint}

The BM reacts strongly with laser and forms welding molten pool during the welding process. Therefore, the size and shape of welded joint is directly affected by the weld pool. The schematic diagrams of top WZ and HAZ width(named $\mathrm{W}_{\mathrm{T} 1}, \mathrm{~W}_{\mathrm{T} 2}$ ), middle $\mathrm{WZ}$ and $\mathrm{HAZ}$ width (named $\mathrm{W}_{\mathrm{M} 1}, \mathrm{~W}_{\mathrm{M} 2}$ ) and bottom $\mathrm{WZ}$ and $H A Z$ width (named $W_{B 1}, W_{B 2}$ ) are shown in Fig. 3(a). Besides, the macro morphology of the cross-section

profile of the bottom-locking welded joint under different welding parameters is shown in Fig. 3(b-d). It is easily seen from Fig. 3 that all welds are in the state of penetration and no obvious defects is found in the welding joints. As for the weld width, there is no doubt that the maximum value appears at the top of WZ, but the area where the minimum value appears cannot be determined. At the same time, it can be roughly observed from Fig. 3 that the HAZ shows two regions with different microstructure. According to the relevant literature, the one closed to WZ is called high temperature heat affected zone(HT-HAZ) and the other closed to BM is called low temperature heat affected zone(LT-HAZ).

The detailed characteristic parameter curves of weld macro morphology under different welding speeds are shown in Fig. 4. It is obliviously seen from Fig. 4 that the weld width is closely related to the welding speed. The specific performance is that with the increase of the welding speed, the weld width becomes smaller and smaller, especially the bottom of the weld seam. In addition, the width of HAZ also shows a certain trend that increases first and then decreases while the welding speed increasing from $1.0 \mathrm{~m} \cdot \mathrm{min}^{-1}$ to $1.5 \mathrm{~m} \cdot \mathrm{min}^{-1}$. Therefore, whether it is in WZ or HAZ, the macro morphology will change with the welding heat input according to what has been discussed above.

\subsection{Micro morphology of welded joint}

Figure 5 shows the microstructural characterization of laser welded bottom-locking joint of TA15 titanium alloy. The microstructure transformation of WZ and HAZ are closely related to the initial microstructure of $\mathrm{BM}$ and welding thermal cycle process. It should be mentioned that the redistribution of joint elements will be limited during the process from metal melting to cooling to room temperature, resulting in the formation of supersaturated martensite in the WZ. As is shown in Fig. 5, WZ is mainly composed of coarse $\beta$ columnar crystal and fine $a^{\prime}$ acicular martensite. The $\beta$ columnar crystal at the top of the WZ grows from the fusion line to the center of the weld. Differently, the $\beta$ columnar crystal in the middle of the WZ grows perpendicular to the fusion line, and equiaxed crystal forms in the middle of the weld. This situation occurs due that the columnar crystal is formed by intergrowth crystallization and epitaxial growth during the solidification process of the weld. In addition, the grain grows preferentially and keeps 
consistent with the fastest heat dissipation direction until it grows to the center of the weld. The temperature and undercooling are relatively high in the middle of the weld, at the same time, the heat is dissipated to both sides at the same time. Before the columnar crystal grows to the center of the weld, the liquid metal in this area has nucleated. Besides, the $\mathrm{a}^{\prime}$ acicular martensite precipitated along different directions in the $\beta$ columnar crystal is distributed in basket shape and crisscross with columnar grains in the WZ according to the content of Fig. 5. Therefore, the $a^{\prime}$ acicular martensite is dense in the weld. But the microstructure in HAZ is complex and uneven, which changes along the fusion line and vertical direction.

Figure 6 shows the microstructure and morphology of weld metal at $1.0 \mathrm{~m} \cdot \mathrm{min}^{-1}, 1.2 \mathrm{~m} \cdot \mathrm{min}^{-1}$ and $1.5 \mathrm{~m} \cdot \mathrm{min}^{-1}$, respectively. It is easily observed from Fig. 6 that there are some differences in the shape and size of $\beta$ columnar crystal in the WZ under different welding speed. Specifically, the smaller the welding speed is, the coarser the shape and size is. Besides, the growth direction of $\beta$ columnar crystal from the fusion line to the weld center in WZ also have a little difference under different parameters. The result is the difference in the amount of $a^{\prime}$ acicular martensite in the WZ. Specifically, with the increase of welding speed, i.e. the decrease of welding heat input, the number of a' acicular martensite decreases gradually, but it is still dispersed, and the directivity is not obvious from Fig. $6(\mathrm{~b})(\mathrm{e})(\mathrm{h})$. Therefore, it can be found that there are more dense $\mathrm{a}^{\prime}$ acicular martensites in the WZ in the case of $1.0 \mathrm{~m} \cdot \mathrm{min}^{-1}$. It should be noted that a lot of twins are existed in the acicular martensite $a$. The increase of the amount of twins is equivalent to the refinement of grains, which can produce strengthening effect on the welded joint. As a result, compared with the welding speed of $1.2 \mathrm{~m} \cdot \mathrm{min}^{-1}$ and $1.5 \mathrm{~m} \cdot \mathrm{min}^{-1}$, the joint of welding speed at 1.0 $\mathrm{m} \cdot \mathrm{min}^{-1}$ has the highest strength and the best performance from the perspective of microstructure. Morever, there are mainly coarse $\beta$ columnar crystals in the middle of the weld, and the growth zone of columnar crystal becomes smaller with the increase of welding speed from Fig. 6 . However, the existence of acicular martensite is rarely seen in the middle of the weld where the temperature is not conducive to the transformation of $\beta$ columnar crystal into acicular martensite.

Furthermore, there are certain initial martensitic a phase and a' phase in HT-HAZ where is close to the weld, but the size and amount of $a^{\prime}$ phase is smaller than that in WZ from Fig. 6(f); there are a small amount of $a^{\prime}$ and $\beta$ and numerous initial a phase in LT-HAZ where is close to the BM from Fig. $6(I)$. As mentioned in Sect. 3.1, the width of HAZ will change to a certain extent under different welding speed. Accordingly, the width of HT-HAZ will also change to a certain extent and the number of various types of organizations in this region will also show certain differences. Besides, it is not different that the grain size of the whole HAZ increases gradually from BM to WZ. As a result, it will make some effect on the mechanical properties.

In order to further explain the characteristics of the microstructure in each region of the joint, the phase transformation is analyzed. In this experiment, the schematic diagram of phase transformation in WZ and HAZ region is shown in Fig. 7(c) and (d). The initial a phase is affected by the laser heat source, and it turns into liquid $\beta$ phase when the phase transformation point is reached. The growth of $\beta$ grains grow 
in the opposite direction of heat dissipation and the diffusionless transformation from $\beta$ phase to acicular martensite $a^{\prime}$ phase occurs due to the high cooling rate, so the microstructure in WZ is composed of $a^{\prime}$ phase. The a phase in HT-HAZ is heated to above the $\beta$-transformation temperature but belower than the melting point, so the microstructure consists of martensitic a phase and a few a phase. The LT-HAZ is heated to below the $\beta$-transformation temperature but higher than the minimum temperature required for microstructure transformation and the cooling rate is relatively slow. Therefore, this region with recrystallizationis a partial transformation zone, and the microstructure is composed of primary a phase, intergranular $\beta$ phase and a small amount of martensitic $a^{\prime}$ phase.

\subsection{Tensile test and fracture analysis}

Tensile tests are conducted at room temperature for the welded joints in this study. However, due to the difference between the thickness of the two plates, a heel block should be added to make the left and right ends in the equal height position. The geometries of the tensile specimens, schematic diagram of tensile test, schematic diagram of fracture location and tensile strength and elongation are shown in Fig. 8.

After the test, the tensile data are sorted out. There are great differences in the fracture location, tensile strength and elongation of weld joint of bottom-locking structure under different welding parameters. It can be observed from Fig. 8(a) that Case 1 is fractured on the BM and the fracture direction is $45^{\circ}$ to tensile direction, which indicates that the joint has high strength and good quality. Differently, Case 2 is fractured at the weld joint, and the fracture trace runs through the WZ and HAZ. The fracture position of Case 3 is the same as that of Case 2, which is also at the weld joint. But the fracture direction is different from that of Case 2, the surface trace line of which is almost perpendicular to the tensile direction. The fracture results show that the joint strength is the best when speed is $1.0 \mathrm{~m} \cdot \mathrm{min}^{-1}$, which is related to the more acicular martensite $a^{\prime}$ in the WZ, as mentioned in Sect. 3.2. The effects of three different welding parameters on tensile strength and elongation are respectively as follows: with the increase of welding speed, the tensile strength first decreases and then increases while the elongation decreases all the time. Specifically, the tensile strength is the largest when the welding speed is $1.5 \mathrm{~m} \cdot \mathrm{min}^{-1}$, which is $999 \mathrm{MPa}$, but the elongation is the smallest, which is $2.7 \%$; the elongation is the largest when it is $1.0 \mathrm{~m} \cdot \mathrm{min}^{-1}$, which is $4.2 \%$. The maximum tensile strength and elongation of the two Cases with fracture position in the weld can reach $89 \%$ and $24 \%$ of the BM of TA15 titanium alloy, which indicates that laser welding with the bottom locked titanium alloy has strength loss phenomenon.

The SEM fracture morphology and high multiple graph of local position of the welded joint with three different welding parameters are shown in Fig. 9. As is shown in Fig. 9(a), the fracture surface of Case 1 is relatively flat and the fracture surface is at an angle of 45 degrees to the direction of tensile stress, which shows obvious characteristics of ductile fracture. From the magnification diagram of the local position, as shown in Fig. 9(b), it can be seen that there are many small and deep dimples that show a state of aggregation state, indicating that the good toughness of the BM. Differently, the fracture surface of Case 2 shows obvious cleavage fracture characteristics and its surface is divided along the diagonal 
line, showing obvious differences between the top and the bottom according to the Fig. 9(c). The upper surface of the fracture is relatively flat and there are no obvious defects. Differently, there are a large number of porosity that appears in a certain aggregation state on the lower surface of the fracture. This phenomenon has a great impact on the mechanical properties of the joint and also explains that why the tensile strength of Case 2 is the lowest. Besides, from the view of the morphology of the fracture surface at high times of the local position, there are also some small and shallow dimples just as shown in Fig. 9(d). In addition, it can be seen from Fig. 9(e) that the fracture surface of Case 3 is relatively uniform, and compared with Case 2, the porosity defects are also reduced a lot. From the magnification of its local position, it can be found that the dimple shape and size distribution on the fracture surface are different. The specific performance is as follows: the size of dimple is larger than that of Case 2, and the dimple aggregation is less obvious than that of Case 1.

In order to further analyze the strength loss of joint, the element analysis is carried out on this part. The composition analysis of the fracture part of Case 2 is shown in Fig. 10. It is not difficult to see from the EDS analysis results that the contents of main elements are dissimilar at different positions of the fracture. And it can be seen from Fig. 10(a-b) that in the dimple of fracture, Al and $\mathrm{V}$ elements have certain burning loss, especially $V$ element, which is almost completely burned. In addition, the content of $\mathrm{Ti}$ around the porosity is lower than that in TA15 titanium alloy, which indicates that the element is seriously burned, and the burning loss of $\mathrm{V}$ element is similar according to Fig. 10(c-d). However, there is an obvious difference that the relative content of Al element around the increases, even higher than that of the BM, which is mainly related to the characteristics of Al. Due to a large amount of burning loss of $\mathrm{V}$, a stable element, the strength of the joint is affected to a certain extent.

\section{Conclusion}

The effect of laser welding speed on the grain morphology and tensile property of TA15 titanium alloy bottom-locking laser welded joint was analyzed theoretically and experimental to some certain. And the conclusions in this experiment are as follows:

1. According to the macro morphology of the weld in this experiment, the width of the top, middle and bottom of the weld gradually decreases along with the increase of the welding speed when the laser power is constant and the change of the bottom weld width is the most obvious. The width of HAZ increases first and then decreases when the welding speed increases from $1.0 \mathrm{~m} \cdot \mathrm{min}^{-1}$ to $1.5 \mathrm{~m} \cdot \mathrm{min}^{-}$ ${ }^{1}$, which is different from that of WZ.

2. The quantity and shape distribution of microstructure in each area are dissimilar under three welding speeds. Specifically, the acicular martensite of WZ gradually decreases and the growth trend of $\beta$ columnar crystal to the weld center is also different when the welding speed increases from $1.0 \mathrm{~m} \cdot \mathrm{min}^{-1}$ to $1.5 \mathrm{~m} \cdot \mathrm{min}^{-1}$. In addition, the aggregate growth zone of columnar crystal at the bottom of weld zone becomes smaller with the increase of welding speed. 
3. In the room temperature tensile test, Case 1 is fractured on the BM, and the other two Cases were fractured on the weld. The maximum tensile strength of the Case with fracture position on the weld can arrive $89 \%$ of $\mathrm{BM}$, which indicated that there was a certain strength loss in the welding process. Besides, it could be known stabilization element-V burning loss through SEM and EDS testing methods.

\section{Declarations}

\section{Funding}

No funding was received for conducting this study.

\section{Conflicts of interest}

The authors declare no competing interests.

\section{Availability of data and material}

Data and materials are available.

\section{Code availability}

Not applicable.

\section{Ethics approval}

Not applicable.

\section{Consent to participate}

Not applicable.

\section{Consent for publication}

All authors have read and agreed to the published version of the manuscript.

\section{Authors' contributions}

The welding experiment was conducted by Jiayao Wang. The grinding and polishing of metallographic samples were completed by Jiayoa Wang and Na Qi. Data processing and manuscript preparation were led by Jiayao Wang with contributions from all authors. 


\section{References}

1. Gao M, Wang ZM, Li XY (2012) Laser keyhole welding of dissimilar Ti-6Al-4V titanium alloy to AZ31B magnesium alloy[J]. Metall Mater Trans A 43:163-172

2. Wang ZW, Shen JQ, Hu SS, Wang T, Bu XZ (2020) Investigation of welding crack in laser weldingbrazing welded TC4/6061 and TC4/2024 dissimilar butt joints[J]. Journal of Manufacturing Processes 60:54-60

3. Emre HE, Arslan S (2019) Effect of laser welding on microstructure and mechanical properties of biomedical Ti6Al4V[J]. Applied Physics A-Meterials Science \& Processing

4. Campos FO, Araujo AC, Munhoz ALJ, Kapoor SG (2020) The influence of additive manufacturing on the micromilling machinability of Ti6AI4V: A comparison of SLM and commercial workpieces[J]. Journal of Manufacturing Processes 60:299-307

5. Li DL, Hu SS, Shen JQ, Zhang H, and Bu XZ (2016) Microstructure and mechanical properties of laser-welded joints of Ti-22Al-25Nb/TA15 dissimilar titanium alloys[J]. J Mater Eng Perform 25:1880-1888

6. Zhan XH, Yan TY, Gao QY, Zhu ZX, Bu HC, Wang ZD (2019) The porosity formation mechanism in the laser welded joint of TA15 titanium alloy[J]. Materials Research Express, 076558

7. Liu G, Wang KH, He BB, Huang MX, Yuan SJ (2015) Mechanism of saturated flow stress during hot tensile deformation of a TA15 Ti alloy[J]. Materials Design 86:146-151

8. Song XY, Qian GL, Zhao MY, Diao WY, Ye WJ, Hui SX (2019) Effect of ultrasonic impact treatment on the residual stress distribution of electron beam welded TA15/BTi-6431S dissimilar titanium alloys[J]. Mater Sci Forum 944:104-109

9. Gu C, Wei YH, Zhan XH, Zhang D, Ren S, Liu HB, Li H (2017) Investigation of welding parameters on microstructure and mechanical properties of laser beam-welded joint of $2060 \mathrm{Al}-\mathrm{Cu}-\mathrm{Li}$ alloy[J]. Int J Adv Manuf Technol 91:771-780

10. Chen C, Xiang YZ, Gao M (2020) Weld formation mechanism of fiber laser oscillating welding of dissimilar aluminum alloys[J]. Journal of Manufacturing Processes 60:180-187

11. Zhang H, Hu SS, Shen JQ, Li DL, Bu XZ (2015) Effect of laser beam offset on microstructure and mechanical properties of pulsed laser welded BTi-6431S/TA15 dissimilar titanium alloys[J], 74. Optics \& Laser Technology, pp 158-166

12. Zhan XH, Wang YB, Liu Y, Zhang Q, Li YB, Wei YH (2016) Investigation on parameter optimization for laser welded butt joint of TA15 alloy[J]. Int J Adv Manuf Technol 84:2697-2706

13. Shen JQ, Li B, Hu SS, Zhang H, Bu XZ (2017) Comparison of single-beam and dual-beam laser welding of Ti-22Al-25Nb/TA15 dissimilar titanium alloys[J]. Opt Laser Technol 93:118-126

14. Wang KH, Liu G, Tao W, Zhao J, Huang K (2017) Study on the mixed dynamic recrystallization mechanism during the globularization process of laser-welded TA15 Ti-alloy joint under hot tensile deformation[J]. Mater Charact 126:57-63 
15. Xu WF, Ma J, Luo YX, Fang YX (2020) Microstructure and high-temperature mechanical properties of laser beam welded TC4/TA15 dissimilar titanium alloy joints[J]. Transactions of Nonferrous Metals Society of China 30:160-170

16. Li JJ, Shen JQ, Hu SS, Zhang H, Bu XZ (2019) Microstructure and mechanical properties of Ti-22Al25Nb/TA15 dissimilar joint fabricated by dual-beam laser welding[J]. Opt Laser Technol 109:123130

17. Liu LM, Hao XF, Du X (2008) Microstructure characteristics and mechanical properties of laser-TIG hybrid welding joint of TA15 titanium alloy[J]. Materials research innovations 12:114-118

18. Jiang XQ, Fan XG, Zhan M, Liang YF (2021) Microstructure dependent strain localization during primary hot working of TA15 titanium alloy: Behavior and mechanism[J]. Materials \& Design, 109589

19. Dang CY, Liu C, Gong BM, Zhang CZ, Liu C, Liu Y (2020) Effect of microstructure inhomogeneity on mechanical properties of different zones in TA15 electron beam welded joints[J]. Transactions of Nonferrous Metals Society of China 30:678-687

\section{Figures}

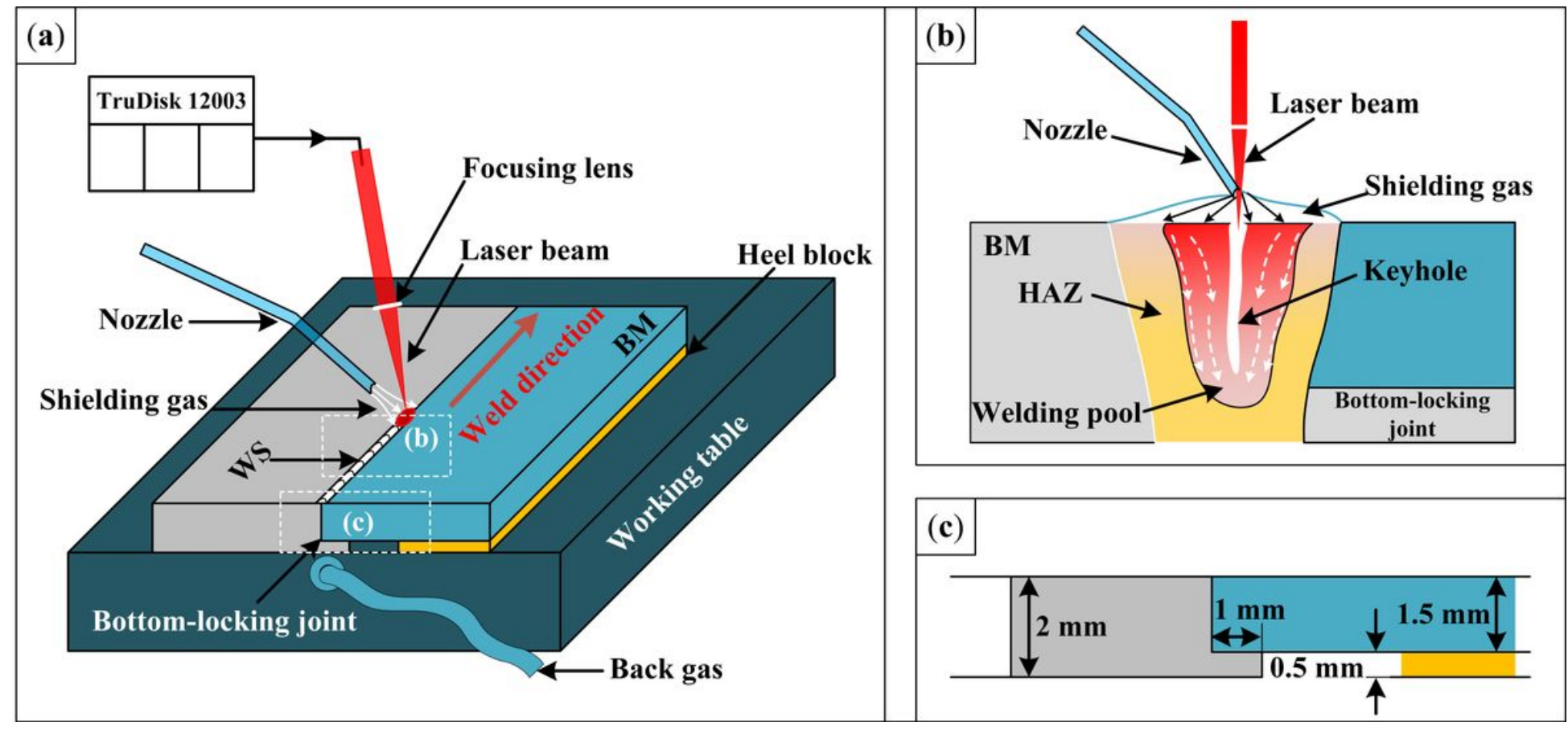

\section{Figure 1}

(a) The schematic of laser welding process; (b) Sectional view of welded joint and (c) The schematic diagram of basic dimensions 


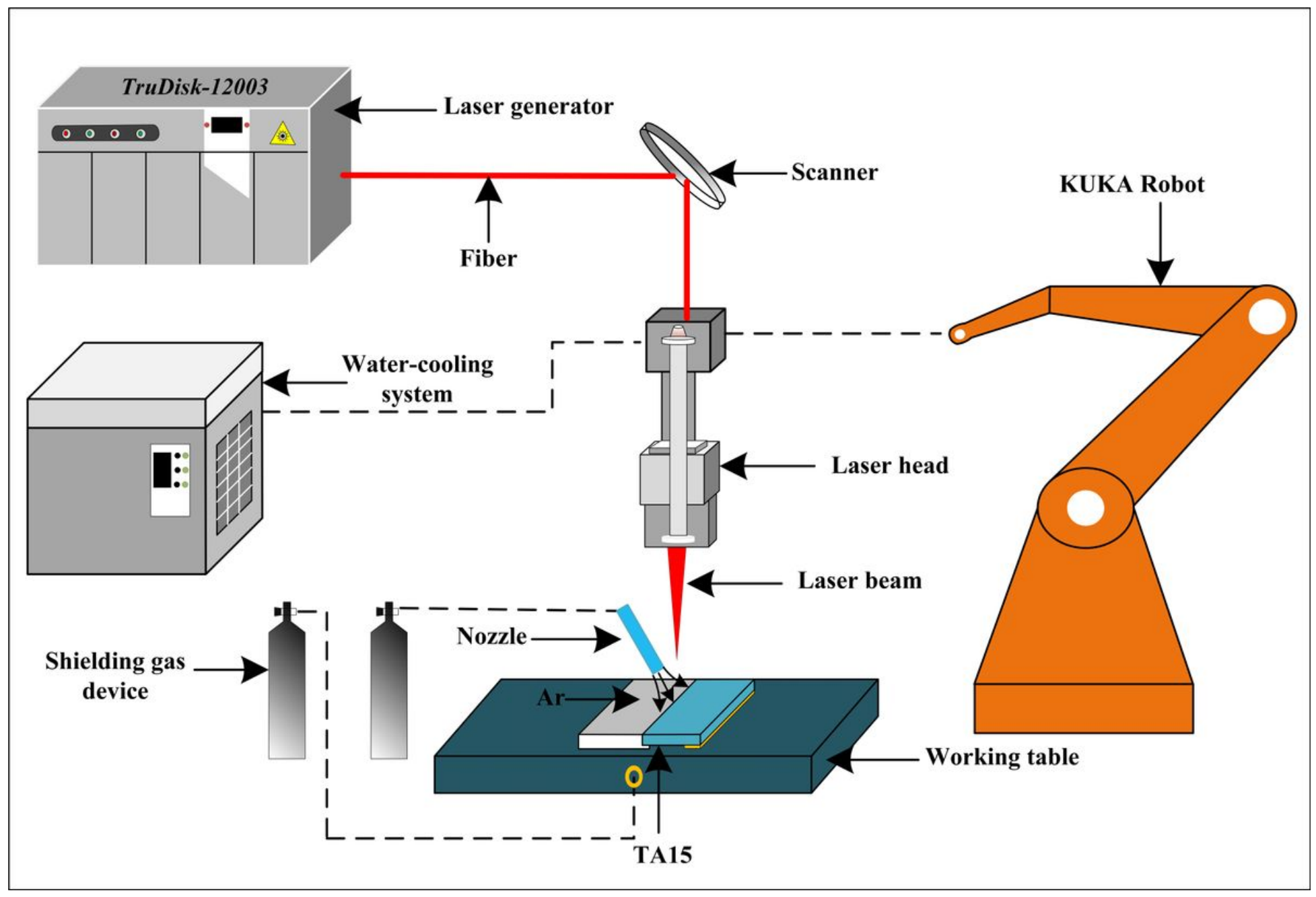

Figure 2

Schematic diagram of laser welding experimental equipment 


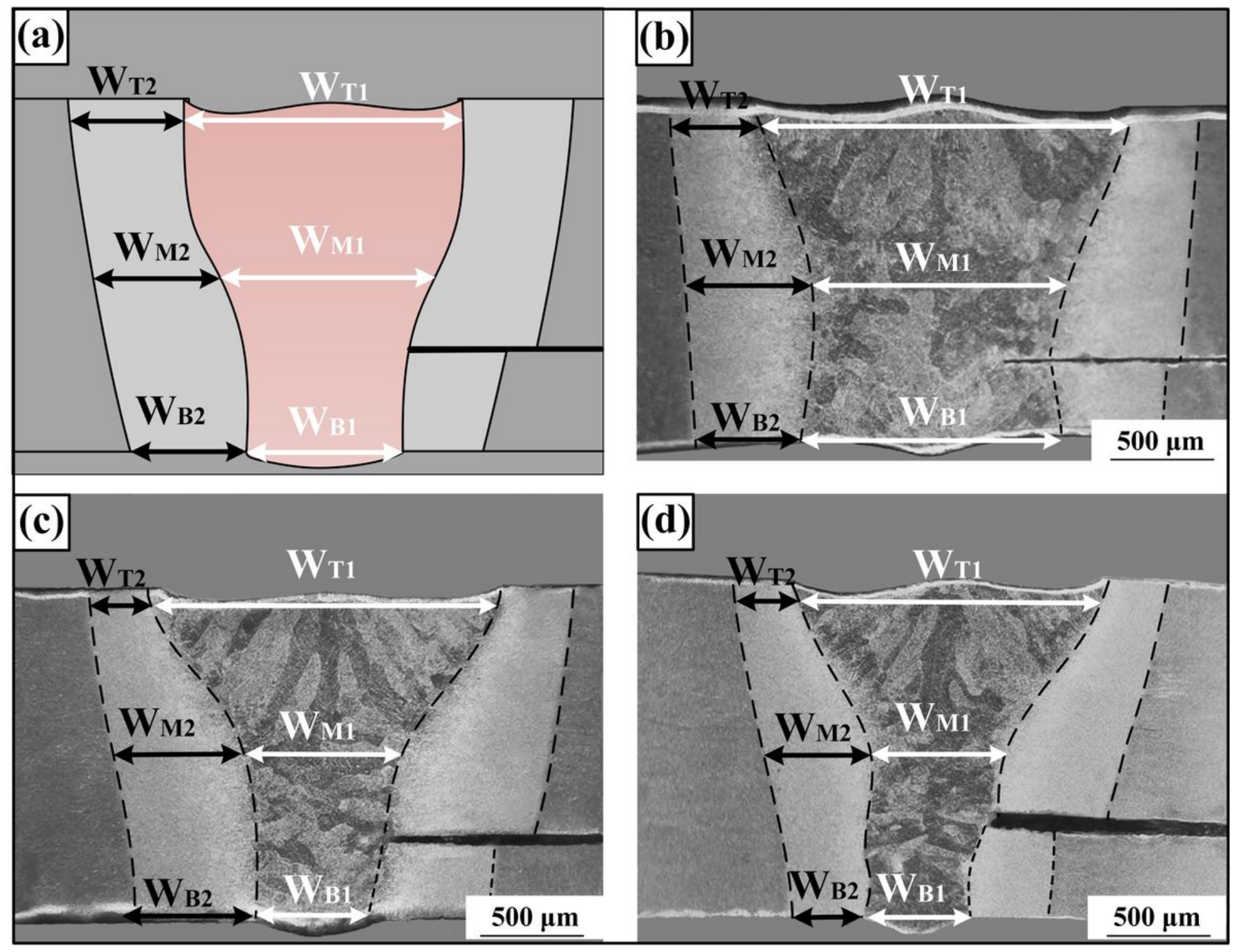

Figure 3

(a) Schematic diagram of measurement positions and Morphology of welded joint cross-section for different welding speed: (b) $1.0 \mathrm{~m} \cdot \mathrm{min}-1$; (c) $1.2 \mathrm{~m} \cdot \mathrm{min}-1$ and (d) $1.5 \mathrm{~m} \cdot \mathrm{min}-1$ 


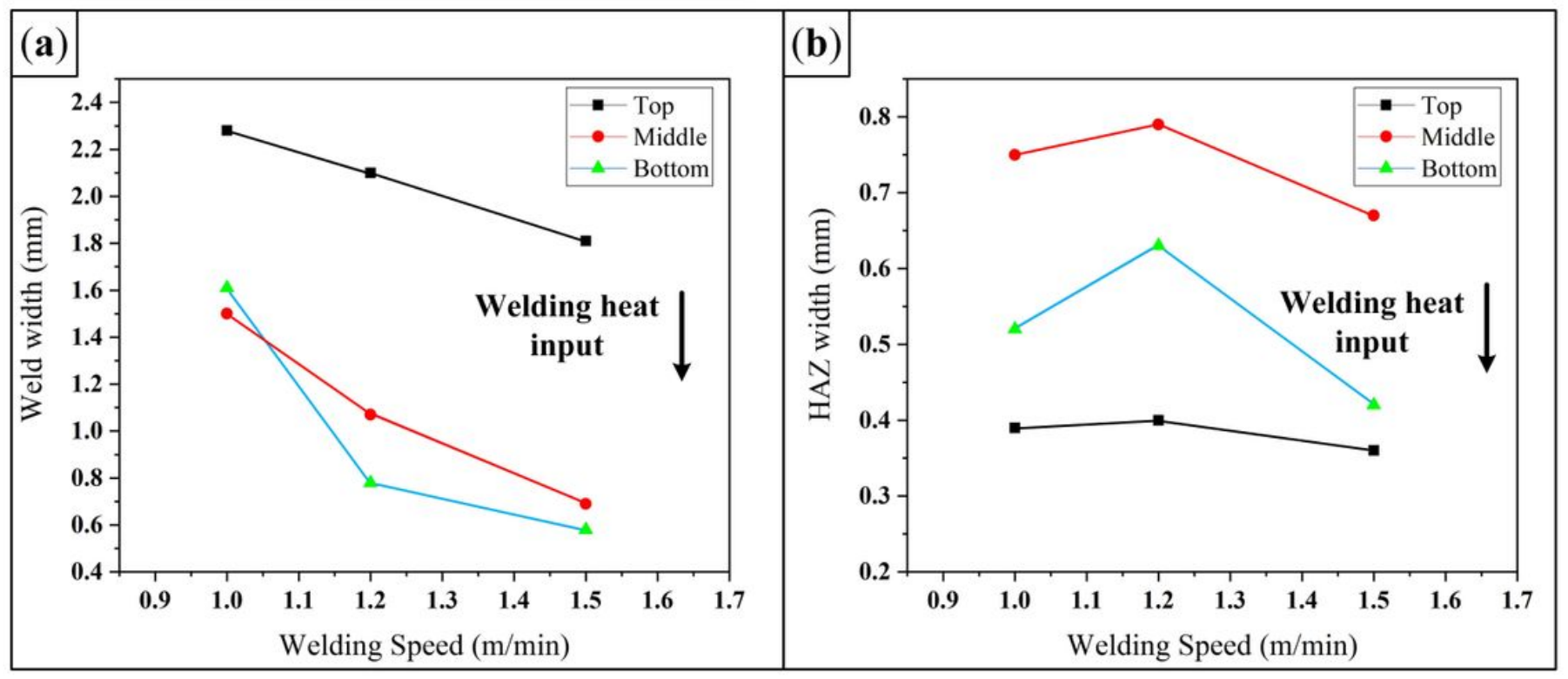

Figure 4

Effect of welding speed on: (a) Weld width; (b) HAZ width

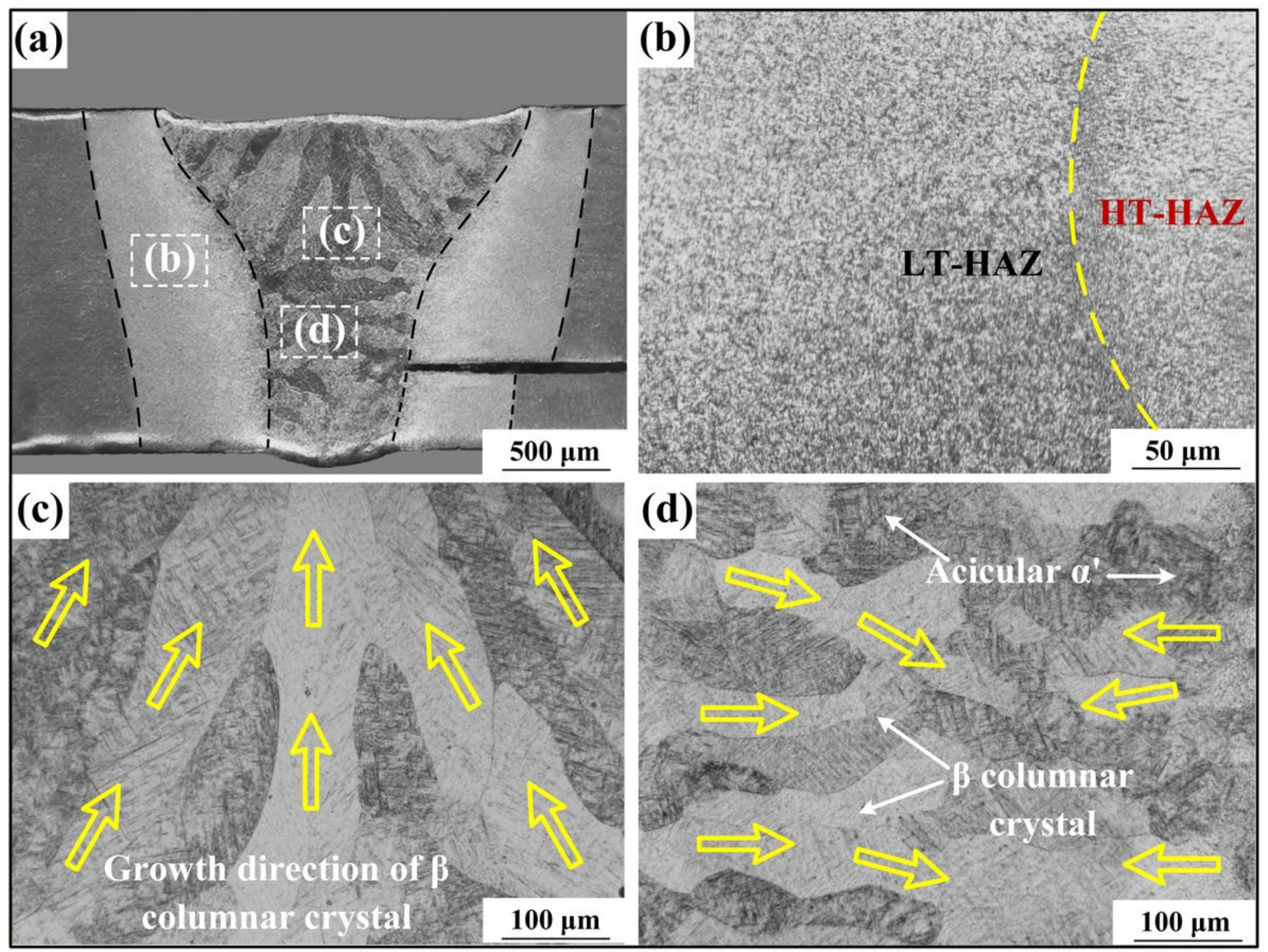


Figure 5

The microstructure of the laser welded bottom-locking joint

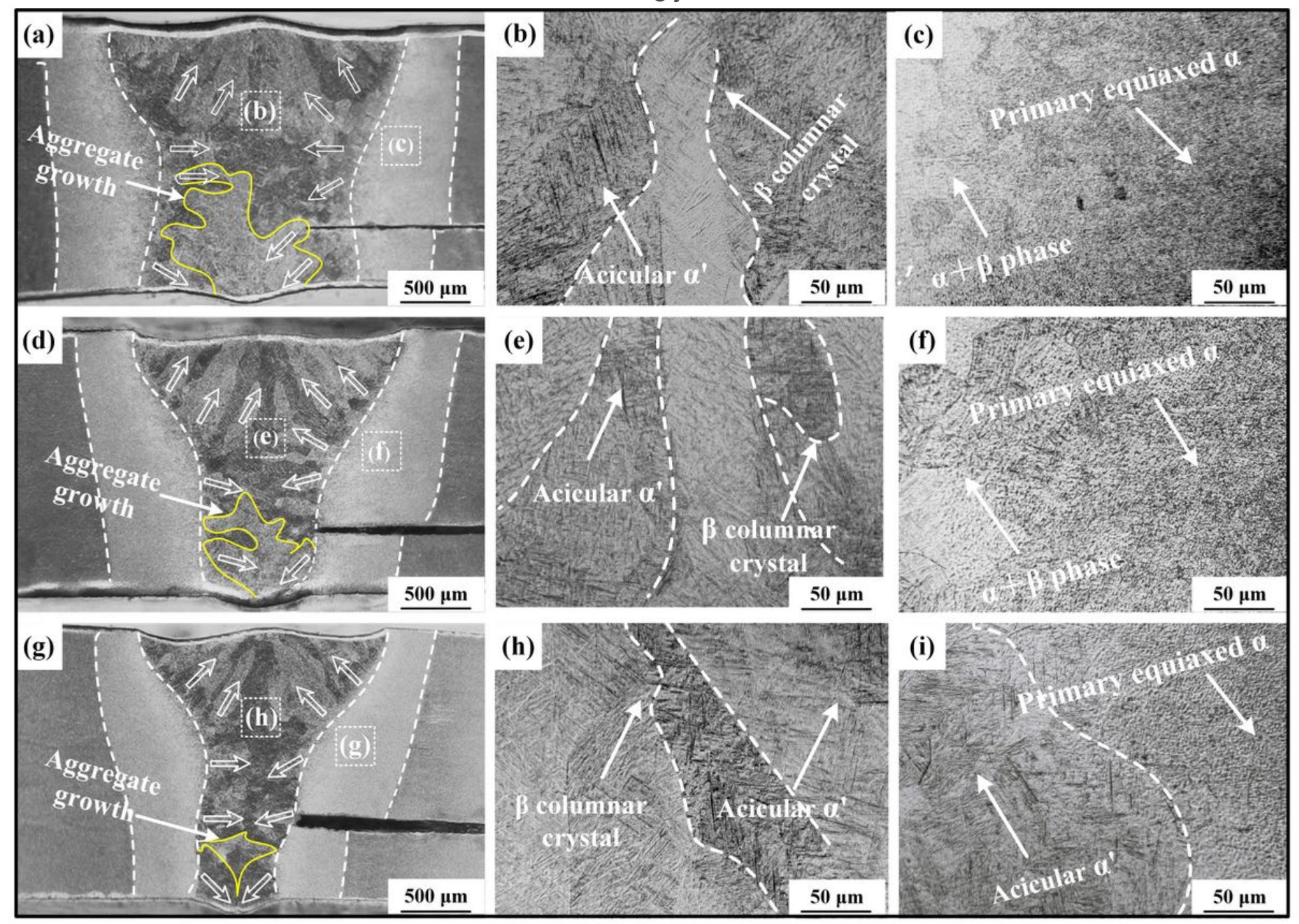

\section{Figure 6}

Microstructure in the WZ and HAZ for different welding speeds: (a-c) $1.0 \mathrm{~m} \cdot \mathrm{min}-1$; (d-f) $1.2 \mathrm{~m} \cdot \mathrm{min}-1$; (g-i) $1.5 \mathrm{~m} \cdot \mathrm{min}-1$ 


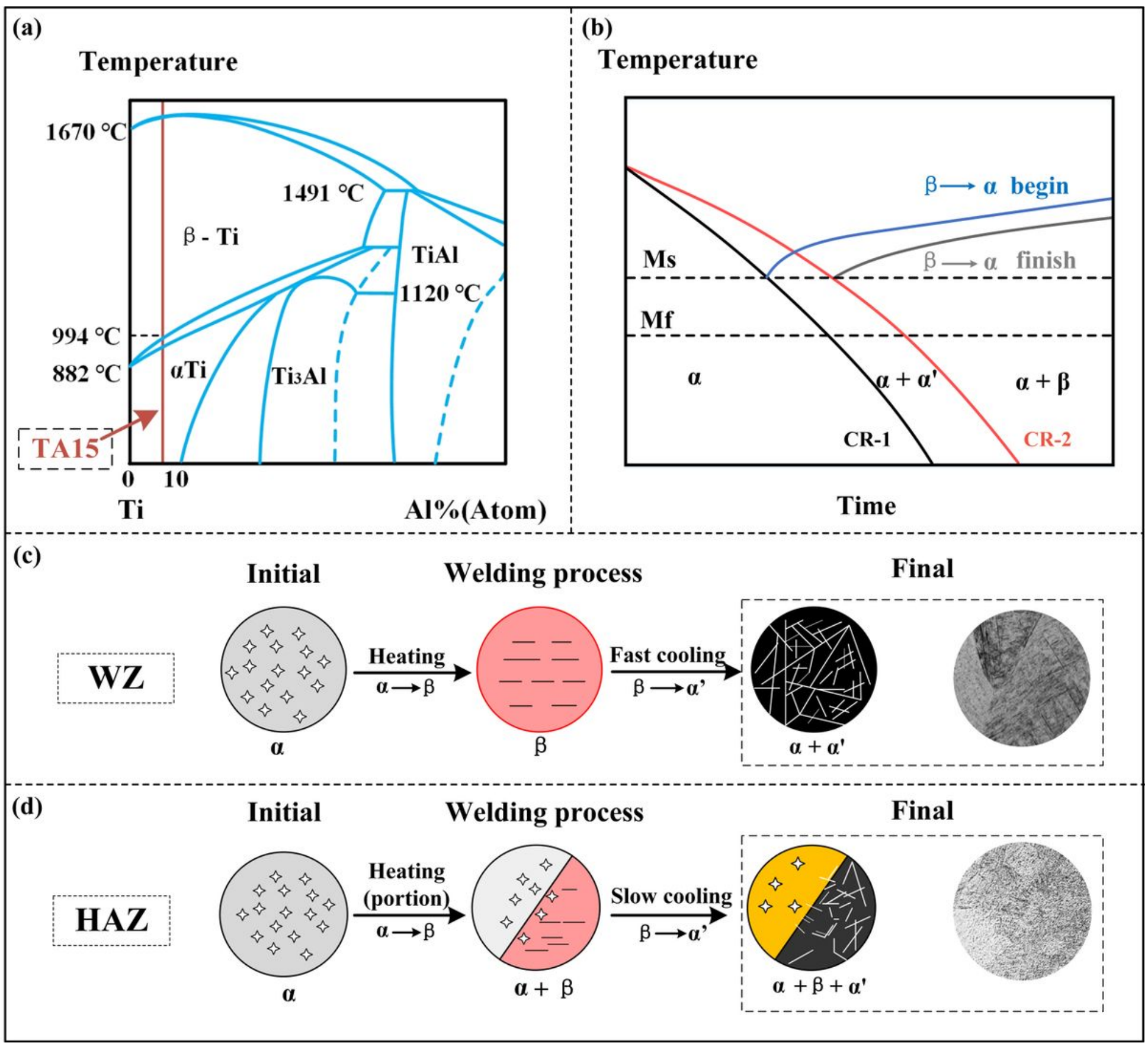

Figure 7

(a) Phase diagram of titanium alloy; (b) CCT diagram of TA15; Schematic diagram of phase transformation in WZ(c) and HAZ(d) 


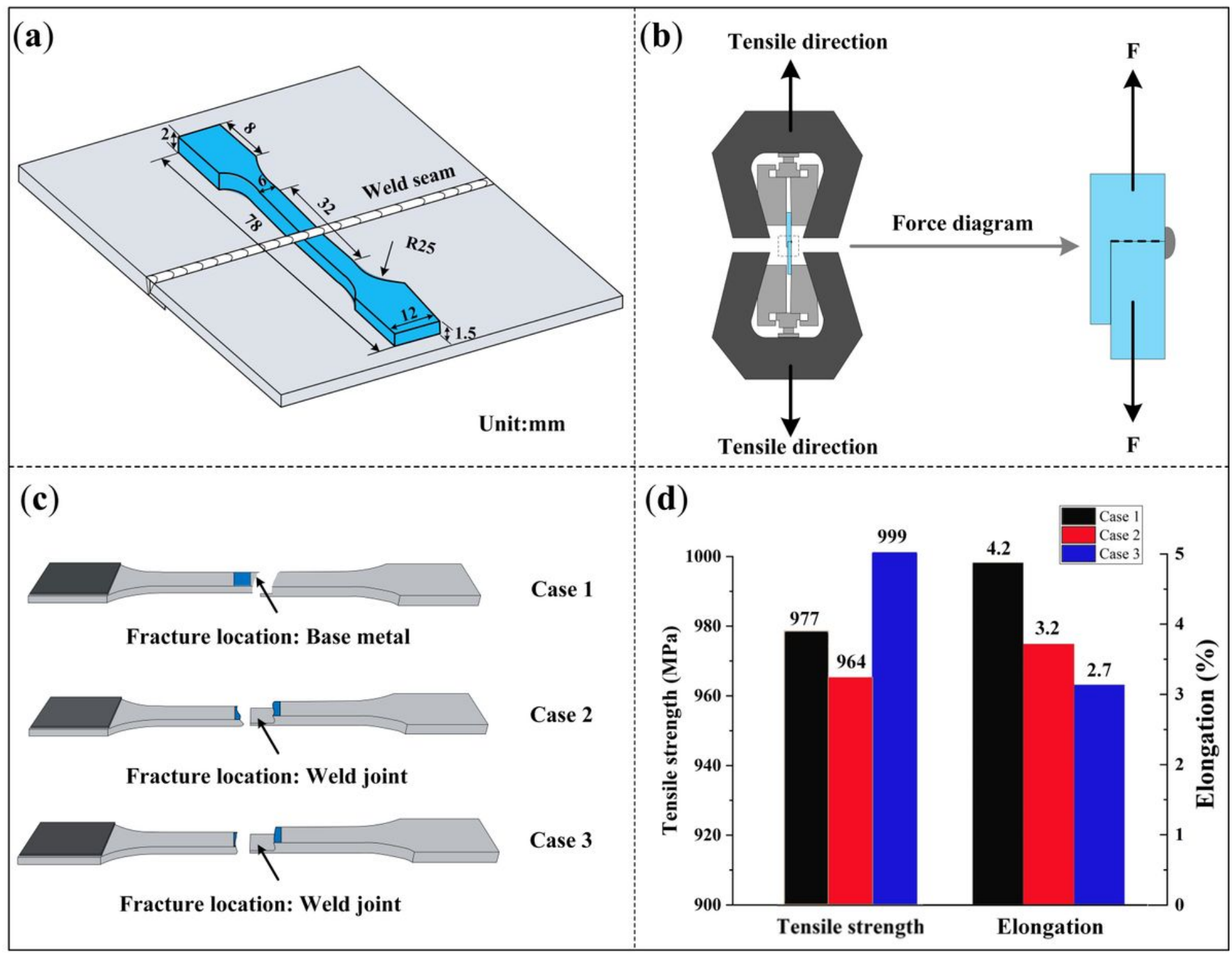

Figure 8

(a) Geometries of tensile test specimens for testing at room temperature (units:mm); (b) Schematic diagram of tensile test; (c) Schematic diagram of fracture location and (d) Tensile strength and Elongation 


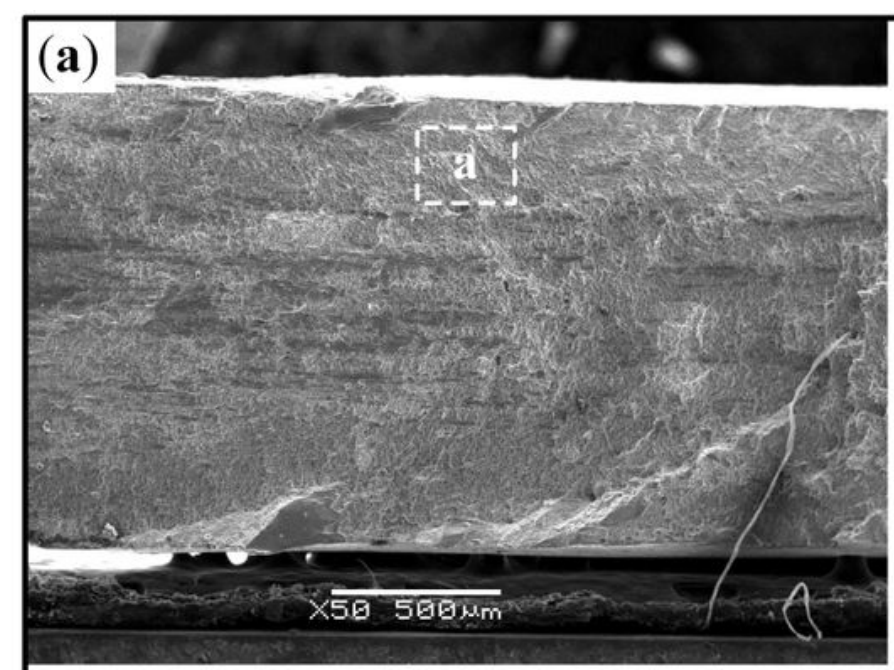

(b)
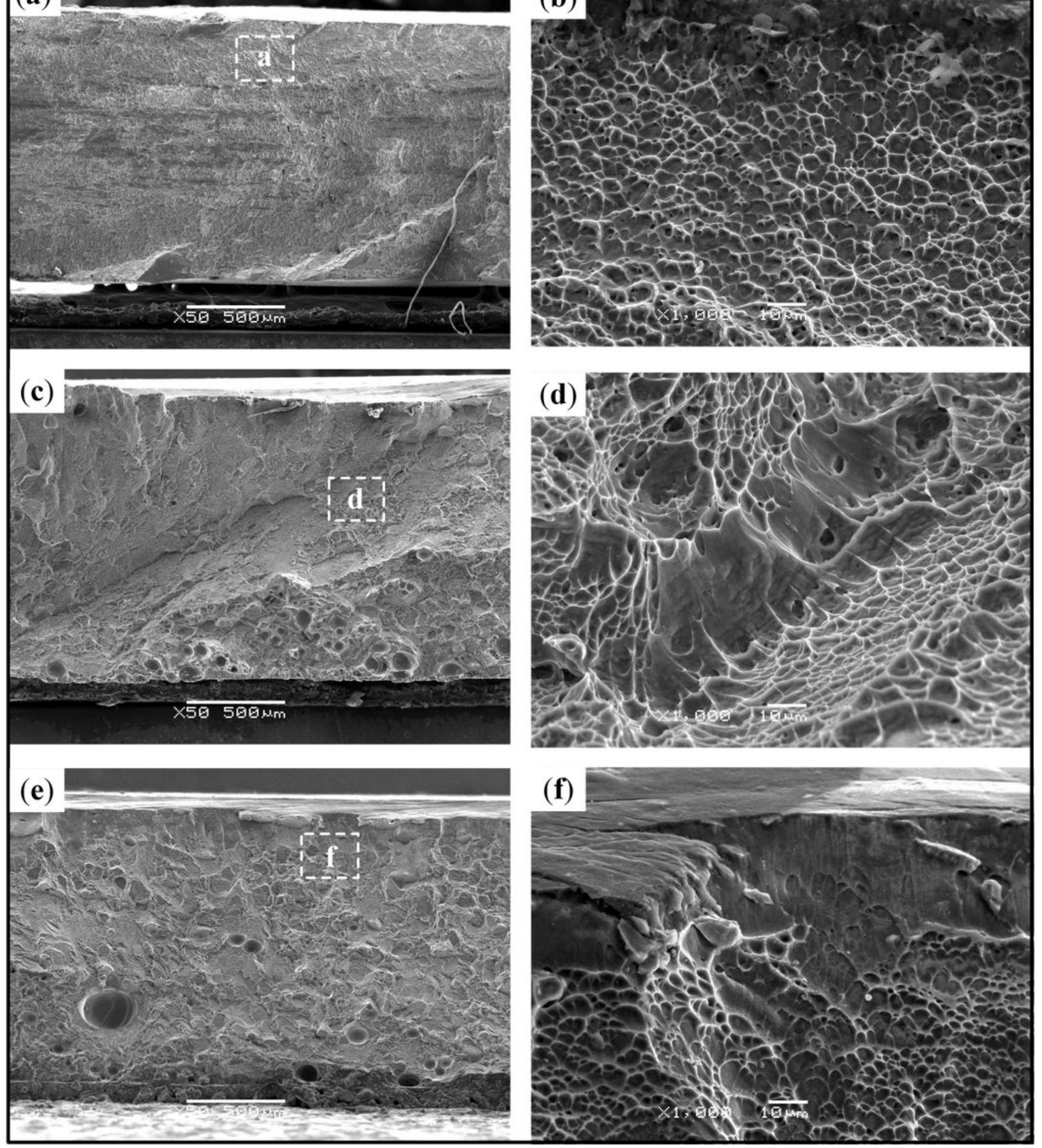

\section{Figure 9}

The tensile fracture morphology of the welded joint with the welding speed of (a-b) $1.0 \mathrm{~m} \cdot \mathrm{min}-1$, (c-d) 1.2 $\mathrm{m} \cdot \mathrm{min}-1$ and (e-f) $1.5 \mathrm{~m} \cdot \mathrm{min}-1$ 

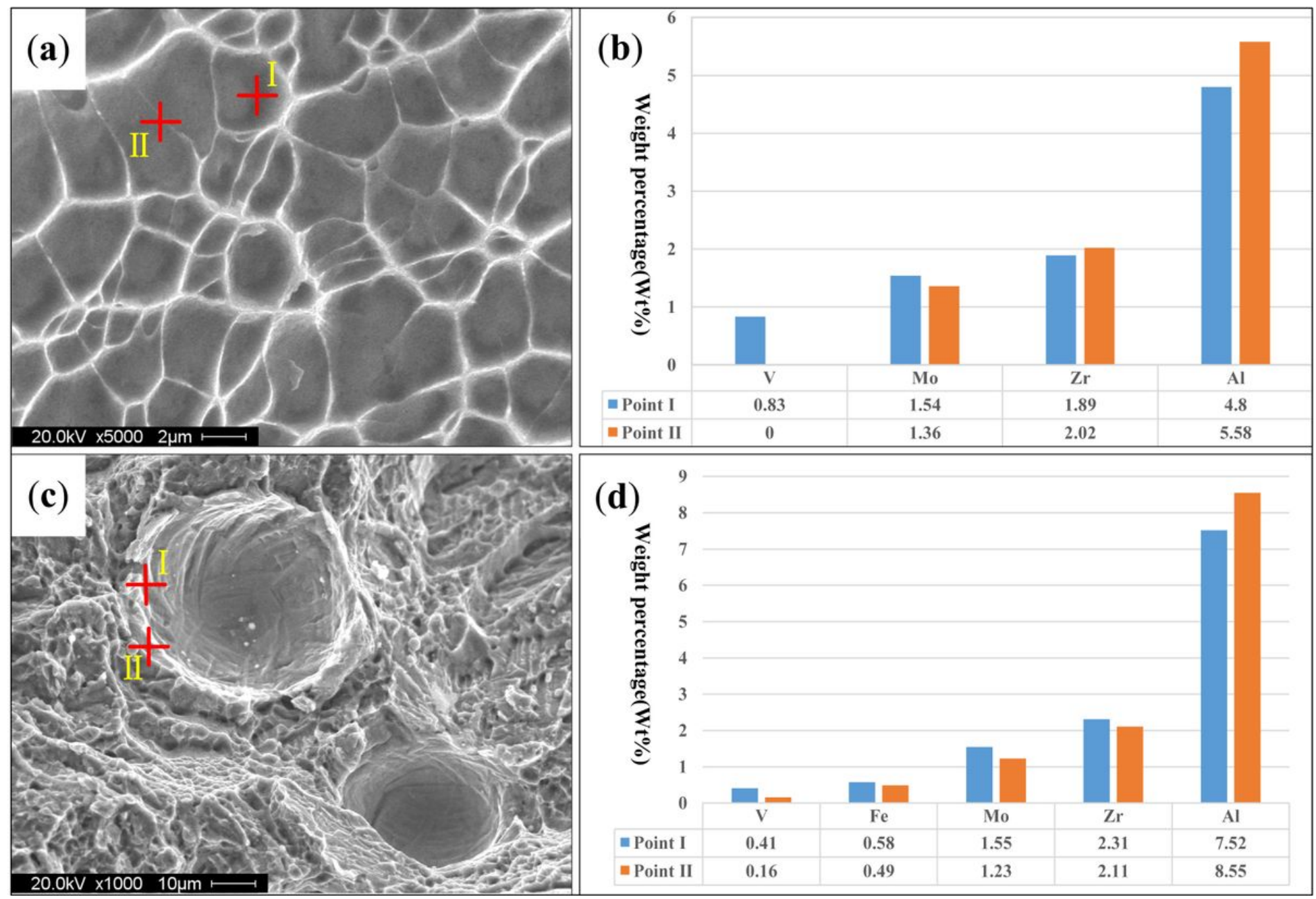

Figure 10

EDS analysis of fracture surface of Case 2: (a-b) surrounding to dimple and (c-d) surrounding to porosity 